\title{
Developmental level and speed of relational concept formation: a possible inverse relationship
}

\author{
H. E. Klugh, Kay Colgan' and Judith A. Ryba \\ ALMA COLLEGE
}

\begin{abstract}
Abstraet
In two studies involving concept problems of different difficulty levels, 1st grade children reached a learning criterion in fewer trials than 4th grade children. A significant interaction was observed between grade level and trials to relearn the concept. Older Ss showed more savings.
\end{abstract}

\section{Problem}

A substantial body of literature supports the generalization that younger children require more time to learn concept-like problems than do older children (Whitecraft, Cobb \& Davis, 1959; Ellis \& Sloan, 1959; Wenar, 1961). The first study reported here grew out of an attempt to explore the relationship between age, interpolated learning and trials to relearn a concept-like problem in elementary school children. The second study was an attempt to verify some unusual results obtained in the initial experiment.

\section{Method}

\section{Study 1}

In the first part of Study 140 children, 10 from each of the first four elementary grades, were presented individually with an adaptation of the Yerkes problem box. This device housed 12 evenly spaced levers so that any one or more could be pushed forward by E toward S. A hidden selector switch enabled $E$ to arrange for one of these bars, when pressed, to sound an electrical buzzer signifying a correct choice. The correct lever was the second from S's right regardless of the number of levers or the specific levers presented. S's were tested individually by being given a series of trials, each consisting of the presentation of from four to nine levers. These were occasionally adjacent but more often scattered throughout the 12 possibilities. If S's first choice at any setting was incorrect he was allowed a second choice at the same setting; each choice constituted a trial. If the first trial at a given setting was correct the setting was changed. Each correct choice was rewarded by the presentation of an $M$ \& $M$ candy. Criterion was met when a sequence of five consecutively correct choices was made.

For half the S's [ matched on the basis of Binet vocabulary (Terman \& Merrill, 1937)] in eachgrade level an additional two concept problems were learned in a similar way. One of these involved choosing the middle bar, the third required the choice of the second bar from S's left. A different series of bar presentations was used for each problem but each $\mathrm{S}$ within a problem group received the same series of settings for a given concept-problem.
One week later S's were tested on trials to relearn the first problem, second lever from the right. Four S's were unavailable for this retest and were dropped from the subsequent analysis.

\section{Results}

The Stanford-Binet vocabulary sub-test revealed expected and significant differences favoring the higher grades. (First and second grades, and third and fourth grades were pooled; $\mathrm{t}=4.96, \mathrm{p}<.01$.) Trials to learn the initial problem provided a surprise. The means by grades were: $1 \mathrm{st}=12.8,2 \mathrm{nd}=25.0,3 \mathrm{rd}=20.5,4 \mathrm{th}=$ 43.7. When these were subjected to a simple analysis of variance $F=3.28, \mathrm{df}=3 / 32, \mathrm{p}<.05$.

The trials to relearn the original concept were recorded for each $\mathrm{S}$ as a proportion of trials required for original learning. These data were subjected to an analysis of variance from which the following $\mathrm{F}$ ratios $\mathrm{e}-$ merged. (For this analysis grades 1 and 2, and grades 3 and 4 were again pooled.) Between grades, $\mathrm{F}=8.90$, $\mathrm{df}=$ $1 / 32, \mathrm{p}<.01$; the $\mathrm{F}$ between conditions (one vs. three problems) and the interaction of grades and conditions were not significant, consequently there is no evidence for a retroactive inhibition effect.

Since the number of problems originally presented was not a significant variable in relearning the initial problem, an additional repeated measures analysis of variance was performed after pooling S's in these two categories. This analysis revealed a significant trials to relearn by grades interaction $F=4.39$, df $=3 / 32$, $\mathrm{p}<.05$. S's in the higher grades had substantially more savings than S's in the lower grades.

It seems that while 4th graders took four times as many trials to learn the concept originally as did 1st graders, the 1st graders showed virtually no savings score one week later.

\section{Diseussion}

The authors concluded that a replication was in order. Particular attention was directed toward the unusual relationship between trials to solve the concept-problems and grade level. The failure to find any appreciable savings by the 1st and 2nd grade children could well have been due to the extremely rapid problem solving of this group. The failure to find a retroactive inhibition effect may have been due to the complex but similar nature of the interpolated problems.

\section{Method}

\section{Study 2}

S's consisted of 161 st grade and 204 th grade children. (These S's were drawn from a school district in a differ- 
ent state from those in Study 1.). The design of Study 2 varied problem difficulty orthogonally with grade level in an attempt to determine the generality of the inverse relationship observed between grade level and speed of concept-problem solving observed in Study 1. The same apparatus was used in Study 2 and both the problems, A and $B$, required the same response, pressing the second lever from S's right. Problem A, the more difficult problem, was presented to S's as it was in Study 1. Problem $B$ was assumed to be easier, since it reduced irrelevant information. It always consisted of presentations of four adjacent levers; it remained a concept problem since which four of 12 levers offered S, and consequently the specific lever considered correct, was varied from trial to trial as in the other forms of presentation. Two modifications of technique were instituted for Study 2. Each S was given a small container of candies following the completion of his trials instead of a candy following each correct trial. In the first study it was possible that upper grade level S's were more likely to have seen the possibility of prolonging the achievement of criteria to maximize the number of candies earned. Ss in Study 2 had to be tested in their own homes rather than in a private room at school and this was often done under less than ideal circumstances; Ss in Study 1 had been tested privately in a special room at their school.

All Ss were again given the vocabulary section of the Stanford-Binet and the groups assigned to more or less difficult problems were matched on this basis.

\section{Results}

Two of the ten 4th graders could not solve the complex problem within 70 settings and two additional subjects were tested in this group. The mediantrials for this total group was 98. which is much higher than the median of 44 for 4 th graders given the same problem in the previous study (Mann-Whitney, $p<.06$ ). Only two of the six 1st graders tested solved the complex problem within 70 settings but these two had reached criterion in about the same number of trials required by the 1st grade group in Study 1.

The simple problem did prove easier than the complex problem. For fourth grade children it was solved in a median of 36 trials compared to a median of 98 trials on the complex problem (Mann-Whitney, $\mathrm{p}<.02)$. The difference between the trials to criterion of the 1st and 4th graders was also significant on the simple (less irrelevant information) problem; and we again observed the inverse relationship. First graders required a median of 7.5 trials, fourth graders required 36.0 trials. (MannWhitney, $\mathrm{p}<.01$ ).

\section{Diseu ssion}

The results of Study 1 receive some support from Study 2; an inverse relationship between grade level and speed of solution on a concept problem is again observed. On the other hand, we find that using the same problem we are unable to replicate the low scores observed in Study 1 for first grade children. We also observe very much higher scores for fourth grade children. In Study 1 all children met criterion after the presentation of 70 different bar settings. It is quite reasonable to expect this difference if the circumstances of testing were more distracting in Study 2. It was our impression that the testing situations provided in Ss' homes were often extremely distracting. This could well have ballooned the scores of some 1st graders on the more difficult problem. On the less difficult problem, where all Ss finished to criterion within 70 trials, the inverse relationship is again demonstrated. This inversion must reverse somewhere along the developmental continuum. Research is presently underway to establish the points of inflection of this function.

\section{References}

ELLIS, N. R., \& SLOAN, W. Oddity learning as a function of mental age. J.comp. physiol. Psychol., 1959, 52, 228-230.

TERMAN, L. M., \& MERRILL, M. Measuring intelligence. Boston: Houghton Mifflin Co., 1937.

WENAR, S. C. Simple concept formation in children as related to age level. Dissert. Abstr., 21, (11), 1961, 3518-9.

WHITECRAFT, R. A., COBB, H. V., \& DAVIS, R. T. Supplementary report: solution of bent-wire detour problems of preschool children. Psychol. Rep., 1959, 5, 609-611.

\section{Note}

1. Now at Bowling Green State University. 